\title{
Ptosis-strabismus-ectopic pupils syndrome
}

INSERM

\section{Source}

INSERM. (1999). Orphanet: an online rare disease and orphan drug data base. Ptosisstrabismus-ectopic pupils syndrome. ORPHA:2999

Ptosis-strabismus-ectopic pupils syndrome is characterised by the association of ptosis, strabismus and ectopic pupils. It has been described in one family (in a mother and three of her children). Transmission is autosomal dominant. 